\title{
Spatial analysis of the neuronal density of aminergic brainstem nuclei in primary neurodegenerative and vascular dementia: A comparative immunocytochemical and quantitative study using a graph method*
}

\author{
Yan Yang ${ }^{\mathrm{a}, \mathrm{b}}$, Konrad Beyreuther ${ }^{\mathrm{b}}$ and \\ Horst P. Schmitt ${ }^{\mathrm{a}, * *}$ \\ ${ }^{\text {a }}$ Department of Neuropathology, University of \\ Heidelberg, Germany \\ ${ }^{\mathrm{b}}$ Center for Molecular Biology, University of \\ Heidelberg, Germany
}

Accepted 16 November 1999

A graph method was employed to analyse spatial neuronal patterns of pontine nuclei with ascending aminergic projections to the forebrain (nucleus centralis superior (NCS), raphes dorsalis (NRD) and locus coeruleus (LC)), in Alzheimer disease (AD), Huntington disease (HD), and vascular (VD) as well as "mixed-type" (VA) dementia, compared with non-demented controls (CO) and a small sample of brains from schizophrenics ("dementia praecox" (DP)). The quantitative evaluations by the "minimal spanning tree (MST)" were complemented by rough neurofibrillary tangle (NFT) counts and by semiquantitative immunohistochemical assessment of amyloid deposition, neuritic plaque formation, and cellular gliosis. The $\mathrm{AD}$ cases showed a significant decline of neuronal density in all nuclei examined, as compared with controls and DP. Neuronal loss was not significant in VD, while the mixed cases with both vascular and Alzheimer-type pathology exhibited pronounced changes of neuronal density. Amyloid deposition occurred almost exclusively in $\mathrm{AD}$ and $\mathrm{VA}$, as a rule, being of moderate degree, except for two presenile AD cases where it was

\footnotetext{
*Presented as poster at the 6th International Conference on Alzheimer's Disease, Amsterdam, 18-23 July, 1998.

${ }^{* *}$ Address correspondence to: Horst P. Schmitt, M.D., Institute of Pathology, Department of Neuropathology, University of Heidelberg, Im Neuenheimer Feld 220-221, 69120 Heidelberg, Germany. Tel.: +49 06221 562629; Fax: +49 06221564566.
}

marked. NFT were significantly increased in all nuclei in $\mathrm{AD}$ and in the VA cases, while they only occasionally appeared beyond age 55 in HD, DP and CO. The four HD cases showed in the NCS and NRD neuronal loss as severe as in AD. This neuronal loss implicates impairment of serotoninergic and noradrenergic neuromodulation as one basic mechanism promoting dementia in $\mathrm{AD}$, VA and perhaps in HD.

Keywords: Neurodegenerative diseases, vascular dementia, aminergic brain stem nuclei, immunocytochemistry, image processing, computer-assisted

\section{Introduction}

Up to now the pathogenesis of the dementia in Alzheimer disease (AD) and other neurodegenerative disorders still remains enigmatic. Current hypotheses put major emphasis on either $\beta$-amyloid deposition in the brain $[11,12,63]$ or the formation of intracytoplasmic neurofibrillary tangles (NFT) in cortical neurons followed by neuronal death $[35,36,41]$. While some authors found positive correlations between cognitive deficit and density of NFT $[9,13,47,48,70]$ and dystrophic neurites [64] in $\mathrm{AD}$, other studies demonstrated that loss of large cortical neurons, formation of NFT, and the amount of $\beta / \mathrm{A} 4$ amyloid deposition did not give satisfactory correlations with the degree of the dementia as assessed by mental scoring procedures $[71,92]$. Instead, better results seemed to emerge from correlation of synaptic pathology with cognitive decline $[26,53,92]$. However, the results changed after correction for non-demented subjects without ADtype pathology $[26,48]$, resulting in the conclusion that 
synaptic markers appeared not to be the best correlates of dementia [26].

In cerebrovascular disease, where multiple cortical infarcts have been conceived to cause dementia ("multi-infarct dementia"), the latter may often be absent, while patients with multiple or large infarcts may never become demented.

One aspect has received comparatively little attention as yet in the consideration of the pathogenesis of the mental deterioration in $\mathrm{AD}$ and perhaps other forms of organic dementia. That is aminergic neuromodulation and its significant influence on normal cognitive functioning $[45,65]$.

The isodendritic core of the brainstem [83] harbours a number of nuclei which form the "ascending reticular activating system (ARAS)" [33], the efferent component of which are ascending aminergic fiber systems projecting to virtually all parts of the forebrain [57]. They originate from the serotoninergic raphe nuclei (nucleus centralis superior (NCS) and nucleus raphes dorsalis (NRD)) $[1,5,6]$, and from the noradrenergic locus ceruleus (LC) $[4,68]$.

The ascending aminergic raphe and LC systems have been shown to be significantly involved as neuromodulators not only in the management of arousal, attentive wakefulness and behavior, but also in that of higher mental functions such as cognitive processing and emotional "coloration" of cognition contents $[45,65,67,84]$. This makes the aminergic nuclei of the brainstem a kind of control center for mental processing and conditioning of the mind, which is also reflected by the fact that the ascending aminergic systems represent main CNS targets via which many neurotropic drugs exert their effect [89]. The integrity of this "center" is essential for appropriate management of conscious perception and cognitive processing [45]. Thus, if the aminergic systems undergo pathologic changes this should have a major impact on the higher mental functions that cannot be neglected in considerations about cognitive impairment.

The present investigation focuses on the pathologic changes of the NCS and the locus ceruleus LC as a contribution to the discussion of a possible role in the pathogenesis of the mental decline in dementing disorders such as AD, Huntington disease (HD), and vascular dementia (VD), as compared with non-demented controls and a small number of schizophrenia cases (“dementia praecox" (DP)).

\section{Materials and methods}

\subsection{Materials}

The present study was performed on a sample of dementia cases which included 30 cases of Alzheimer disease ((AD), 22 females and 8 males, ratio $2.8: 1$, age range 41-93, mean 79.6 years), four cases of Huntington disease (HD, two males and two females, aged $57-75$, mean 64.3 years), nine cases of vascular dementia (VD) including hypertensive encephalopathy of common type and of Binswanger's subcortical type (two males and seven females aged 43-77, mean 63.3 years), and seven cases of "mixed type" dementia (dementia with both prominent vascular and AD type pathology (VA), three males and four females aged 6894 , mean 82.3 years). Finally, 31 non-demented controls (CO, 15 males and 16 females aged 21-111, mean 74.2 years) and four cases of schizophrenia (DP) as examples of a form of dementia still lacking distinctive histopathology [3] (one male and three females aged $51-73$, mean 66.0 years) were included in the evaluation. (The 111 year-old control case was the oldest German citizen when she died due to cardiac failure in excellent mental condition.)

The AD cases were mostly senile dementias, only two being presenile, one of them with familial background. All cases had a clinical record of progressive mental deterioration and had been classified as dementias of the Alzheimer type on the basis of considerable allo- and neocortical amyloid and tangle pathology, fulfilling the "consensus recommendations" [7,8]. With respect to the extent and distribution of tangle pathology they corresponded to the stages IV-VI of Braak and Braak [18]. The AD cases had been collected randomly over a period of more than 15 years from outside hospitals and from the Heidelberg University Department of Pathology.

\subsection{Methods}

\subsubsection{Histologic processing and staining}

The brains were removed at autopsy and fixed in 6$8 \%$ buffered formalin for at least one week to several weeks prior to neuropathological examination. The postmortem delay varied around a mean of 24 hours with a range of 7-71 hours.

Thorough neuropathological examination by coronal sectioning included tissue sampling of 15 cortical and subcortical regions following a standardized protocol. The specimens were processed in the con- 

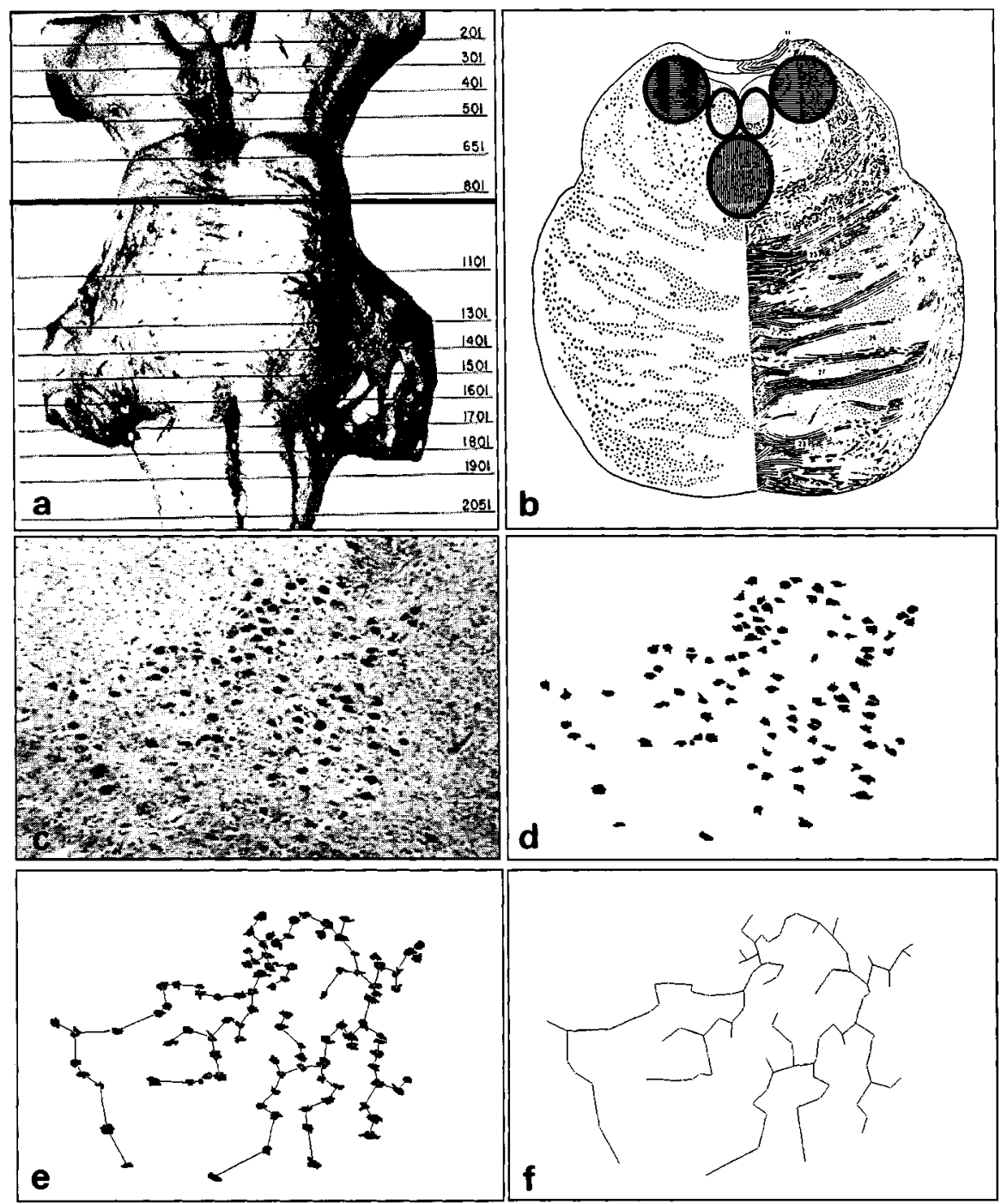

Fig. 1. (a, b) Lower brainstem with cross sectional level selected for the present evaluations ((a) from Olszewski and Baxter [77, p. 19]; (b)

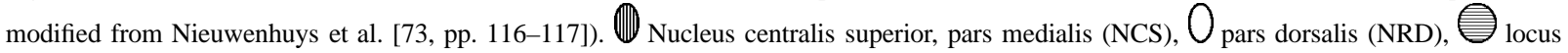
ceruleus (LC)). (c-f) segmentation of large neurons in the locus ceruleus, as an example (c, d) and construction of the "minimal spanning tree" (MST) (e, f). For details see text.

ventional way for paraffin-embedding. In addition to preparations from all regions for routine microscopic examination, seven to ten 3-4 $\mu \mathrm{m}$ thick serial sections were cut for special staining, including immunocytochemistry, from the pons at a level of about 10 millimeters below the rostral border, matching the level 801 of Olszewski and Baxter [77] (Fig. 1a). The sections included the pars medialis (centralis) of the nucleus centralis superior (NCS), its pars dorsalis, nowadays classified with the nucleus raphes dorsalis (NRD) [6], and the rostral part of the locus ceruleus (LC) (Fig. 1b).
Selected sections were stained according to Nissl for neuronal perikarya, to Bodian for neurofibrillary tangles, and with Luxol-Fast-Blue for myelin. Parallel slides were processed for immunocytochemistry by the PAP method, using nickel/cobalt for enhancement of the DAB chromogen. The employed antibodies are listed in Table 1 . The monoclonal antibodies $\mathrm{W}_{0-2}$ to $\beta / \mathrm{A} 4$ and $22 \mathrm{C} 11$ to APP required 20 minutes microwave pretreatment of the paraffin slides $[86,100]$. For negative control the primary antibodies were substituted by PBS. No reaction occurred in the control slides. 
Table 1

Antibodies used for immunocytochemical staining

\begin{tabular}{|c|c|c|c|c|c|}
\hline $\begin{array}{l}\text { Anti- } \\
\text { body }\end{array}$ & Source & $\begin{array}{c}\text { Type } \\
\text { (species) }\end{array}$ & $\begin{array}{l}\text { Working } \\
\text { dilution }\end{array}$ & MWO & $\begin{array}{l}\text { Target } \\
\text { (sequence) }\end{array}$ \\
\hline $\mathrm{W}_{0-2}{ }^{1}$ & $\mathrm{Id} / \mathrm{By}$ & $\begin{array}{c}\mathrm{mAB} \\
\text { (mouse) }\end{array}$ & $1: 100$ & + & $\begin{array}{l}\beta / \mathrm{A} 4(1-40) ; \\
\text { (to aa } 1-16)\end{array}$ \\
\hline $22 \mathrm{C} 11^{2}$ & $\mathrm{Mu} / \mathrm{By}$ & $\begin{array}{c}\mathrm{mAB} \\
\text { (mouse) }\end{array}$ & $1: 100$ & + & APP (aа 66-81) \\
\hline Tau2 & SIGMA & $\begin{array}{c}\mathrm{mAB} \\
\text { (mouse) }\end{array}$ & $1: 1000$ & - & $\begin{array}{l}\text { cytoskeletal tau } \\
\text { protein and NFT }\end{array}$ \\
\hline GFAP & SIGMA & $\begin{array}{c}\mathrm{pAB} \\
\text { (rabbit) }\end{array}$ & $1: 300$ & - & $\begin{array}{l}\text { glial fibrillary } \\
\text { acidic protein }\end{array}$ \\
\hline CD68 & DAKO & $\begin{array}{c}\mathrm{mAB} \\
\text { (mouse) }\end{array}$ & $1: 100$ & - & $\begin{array}{l}\text { macrophages } \\
\text { and microglia }\end{array}$ \\
\hline
\end{tabular}

By $=$ Beyreuther, $\mathrm{Id}=\mathrm{Ida}, \mathrm{mAB}=$ monoclonal antibody, $\mathrm{MWO}=$ microwave oven, $\mathrm{Mu}=$ Multhaup, $\mathrm{NFT}=$ neurofibrillary tangles, $\mathrm{pAB}=$ polyclonal antibody.

${ }^{1}[40],{ }^{2}[95]$.

\subsubsection{Black-and-white image analysis}

The nucleus centralis superior (NCS), the dorsal raphe nucleus (NRD) (pars dorsalis of the NCS), and the locus ceruleus (LC) on both sides (Fig. 1b) were analyzed by black-and-white image analysis (BWIA) and evaluated for their neuronal density by means of a graph method called the "minimal spanning tree" (MST) $[28,85,88]$ (Fig. 1(c-f)).

For image analysis a black-and-white video camera was used to record microscopic pictures from the Nissl stains at a low-power magnification $(\times 50)$. The recorded area represented a field of 1.1 by $1.7 \mathrm{~mm}$ $\left(1.87 \mathrm{~mm}^{2}\right)$. Since the NCS comprises an area of about $2.5-3$ by $1.5-2 \mathrm{~mm}$ on pontine cross sections at level 801, two fields, adequate to cover the major part of the NCS, were recorded from the cranial and the caudal half of the nucleus. Representative fields were also recorded from the NRD (pars dorsalis of the NCS) and from the LC on both sides.

The microscope pictures were first directly displayed on a video control monitor and then processed by a computer containing a real-time video digitizer (Screen Machine II ${ }^{\circledR}$, Fast Multimedia AG, München) as a frame-grabber.

The digitalized images were further processed semiautomatically by means of interactive thresholding using a commercial image analysis software (IMAGINE ${ }^{\circledR}$, Begemann \& Niemeyer Softwareentwicklung GbR, München) to segment the 20-50 $\mu \mathrm{m}$ diameter large neurons [77]. After setting an adequate gray value threshold in order to attain the optimal contrast, the neurons were displayed as gray value images on a HRC monitor with a resolution of $1024 \times 768$ pixel, the gray value scale ranging from 0 (black) to 255 (white) (Fig. 1c).

Thereafter, the images were binarized and unspecific structures (vessels, glial cells, small neurons, etc.) eliminated by setting an interactive scrap level. Still remaining non-specific objects were removed manually, constant reference being made to the original microscopic picture on the video monitor. Overlapping objects were separated manually. Only neurons with nucleus were segmented (Fig. 1d). On the resulting images with the large neurons the MST was constructed by means of a common algorithm described in detail by Kolles et al. [52], according to Prim [79]. The algorithm was provided by the software program IMAGINE $^{\circledR}$. It employs the computed object coordinates, calculates the gravitation centers of the object areas and uses the former as vertices to become linked by the shortest connections (edges) [52] (see also Fig. 1(e-f)).

From the MST in Fig. 1f the following parameters were calculated and expressed as relative values (pixel sizes) for each case: the number of edges (MSNE), the mean edge length (MMEL), the standard deviation (MSSD), and the coefficient of variation (MSCV).

\subsubsection{Graphs and trees}

A graph is a construct where points (nodes, vertices) are connected by linear edges (lines, paths). Relationship is indicated by the presence, lack of relationship by the absence of an edge between two vertices. In a weighted graph, a value has been attributed to every edge [88].

In a connected graph every pair of vertices is connected by at least one edge. A minimally connected 
graph contains only one edge between every pair of vertices. If a number of edges but no vertices are missing, a minimally connected graph attains the form of a tree, called spanning tree. The minimal spanning tree (MST) (Fig. 1(e,f) is a minimally connected graph in which the formation of circles is omitted and the sum of the weighted edges is a minimum. As a result, the number of edges $\left(N_{\mathrm{E}}\right)$ is always one less than the number of the vertices $\left(N_{\mathrm{V}}\right)$. Therefore, in calculations and correlations the number of edges straightly parallels the number of objects $\left(N_{\mathrm{V}}=N_{\mathrm{E}}+1\right)$, so that each can substitute for the other.

Graphs are useful for the parametrization of spatial relationships between objects [75]. In addition, they constitute geometrical representations of networks.

\subsubsection{Statistics}

Data analysis and statistical calculations were performed by means of the SAS/STAT ${ }^{\circledR}$ System ORLANDO II for Windows, Release 6.12 TS020, SAS Institute Inc., Cary, NC, USA.

The Kolmogorov-Smirnov test was used to check for normal distribution of the variables. If the latter could be demonstrated or deviations from normality were not excessive, the robust Student's $t$-test was used to assess the two-tailed significance probability of the differences between group means, using the pooled variance estimate $s^{2}$. The null hypothesis was rejected at $P<0.05$. Analyses of variance were performed by means of the General Linear Models (GLM) procedure, employing the main-effects model with different estimable functions. The GLM procedure is basically a regression model which computes $F$ values for the impact of independent variables on dependent ones [90]. However, if the target variable is a class variable a regression model changes to an analysis of variance (ANOVA for the unbalanced case) [87]. Since $F$ is sensitive to deviations from normality, calculations with the GLM procedure were also performed, for control, on rank transformed values of the independent variables [22].

(Including "age" as an independent variable in the GLM evaluations replaced the common "agematching" of the controls.)

In addition to the graph analyses, neurofibrillary tangles (NFT) were roughly counted in the Bodian stains, controlled by the anti-tau preparations (see also [29]). The results were expressed both in absolute numbers (NNFT) and as "tangle coefficients" (NFCO), i.e., the absolute number of NFT divided by the number of segmented neurons. Further histologic features, such as the amounts of amyloid pathology (AMPA) and cel- lular gliosis (GLIO) were assessed semiquantitatively by light microscopy and expressed in ordinal terms (AMPA: $0 / 1+/ 2+/ 3+$; GLIO: $0 / 1+/ 2+$ ). All evaluations were performed by two persons for control.

\section{Results}

Three examples are shown in Fig. 2 which illustrate the change in neuronal density and spatial arrangement as reflected by the shape of the related MST in the evaluated nuclei (NCS, NRD, LC) in an AD patient compared with an age-matched control. The results of the graph analysis are summarized by Table 2 for the parameters numbers of edges (MSNE), mean edge length (MMEL), and coefficient of variation (MSCV), while Table 3 provides the percent change for all MST parameters in the disease groups as compared with the controls.

In Alzheimer disease (AD), the number of large neurons, represented by the number of edges (MSNE) was significantly decreased in the nucleus centralis supe-
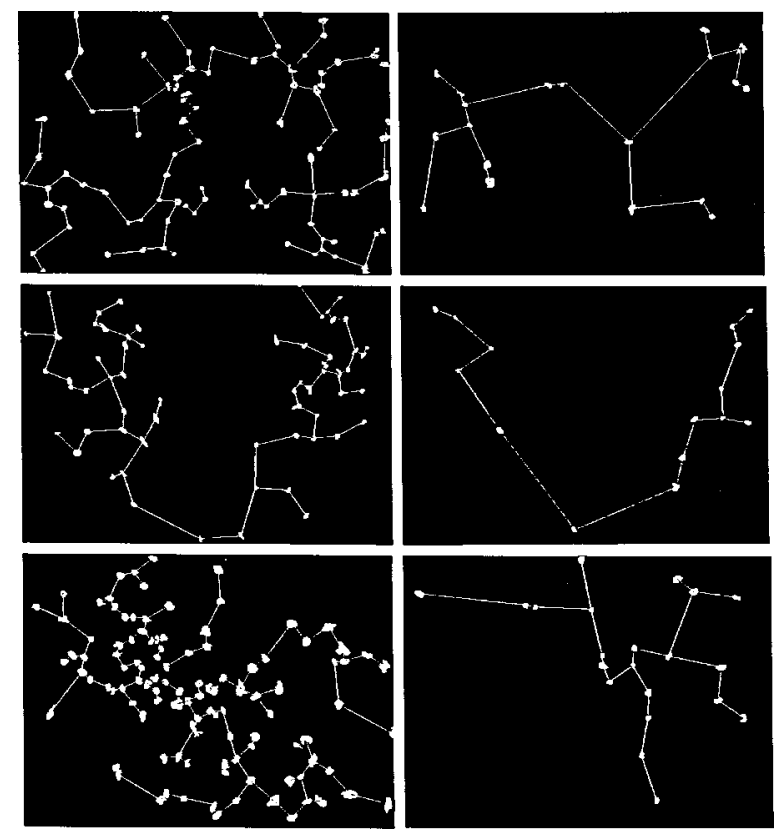

Fig. 2. "Minimal Spanning Tree" (MST) displays of neuronal patterns in a 41 year-old female with familial presenile AD (right column), compared with an age-matched male control case (left column). Top: NCS (left $=$ CO: MSNE $=89$, MMEL $=36.7$ pixel; right $=\mathrm{AD}, \mathrm{MSNE}=18, \mathrm{MMEL}=73.3$ pixel). Middle: NRD (left $=\mathrm{CO}: \mathrm{MSNE}=62, \mathrm{MMEL}=38.5$ pixel; right $=\mathrm{AD}: \mathrm{MSNE}=14$, MMEL $=73.9$ ). Bottom: LC (left = CO: MSNE $=110$, MMEL $=$ 29.1 pixel; right $=\mathrm{AD}: \mathrm{MSNE}=23, \mathrm{MMEL}=56.2$ pixel). $(\mathrm{MSNE}$ number of edges, MMEL mean edge length.) 
Table 2

Results of the graph analysis with the MST

\begin{tabular}{|c|c|c|c|c|c|c|c|c|c|c|c|c|}
\hline \multicolumn{13}{|c|}{ Nucleus centralis superior, pars medialis (NCS) } \\
\hline & \multicolumn{4}{|c|}{ MSNE } & \multicolumn{4}{|c|}{ MMEL } & \multicolumn{4}{|c|}{ MSCV } \\
\hline & Mean & $\pm \mathrm{SD}$ & $\pm \mathrm{SE}$ & $P^{*}$ & Mean & $\pm \mathrm{SD}$ & $\pm \mathrm{SE}$ & $P^{*}$ & Mean & $\pm \mathrm{SD}$ & $\pm \mathrm{SE}$ & $P^{*}$ \\
\hline $\mathrm{AD}$ & 91.8 & 42.02 & 7.7 & $*$ & 49.5 & 16.9 & 3.1 & $*$ & 64.2 & 13.3 & 2.4 & $*$ \\
\hline DP & 126.0 & 78.0 & 39.0 & ns & 36.8 & 10.4 & 5.2 & ns & 55.2 & 10.1 & 5.1 & ns \\
\hline HD & 78.5 & 30.0 & 4.9 & $*$ & 57.5 & 16.5 & 8.6 & $*$ & 58.9 & 3.2 & 1.6 & $\mathrm{~ns}$ \\
\hline VA & 99.9 & 50.5 & 18.9 & ns & 49.7 & 15.6 & 5.9 & $\mathrm{~ns}$ & 57.2 & 7.3 & 2.7 & $\mathrm{~ns}$ \\
\hline VD & 116.7 & 41.1 & 13.7 & ns & 44.2 & 14.5 & 4.8 & $\mathrm{~ns}$ & 58.5 & 7.4 & 2.5 & $\mathrm{~ns}$ \\
\hline$C O$ & 129.9 & 44.4 & 7.9 & - & 42.2 & 12.5 & 2.3 & - & 56.6 & 7.6 & 1.4 & - \\
\hline \multicolumn{13}{|c|}{ Nucleus raphes dorsalis (NRD, pars dorsalis of NCS) } \\
\hline $\mathrm{AD}$ & 48.3 & 28.1 & 5.1 & $*$ & 47.5 & 23.4 & 4.3 & $*$ & 57.9 & 11.9 & 2.2 & $\mathrm{~ns}$ \\
\hline DP & 84.3 & 56.4 & 28.2 & ns & 34.9 & 11.4 & 5.7 & ns & 60.5 & 5.3 & 2.6 & ns \\
\hline HD & 51.8 & 13.1 & 6.6 & ns & 40.3 & 5.4 & 2.7 & ns & 55.9 & 12.7 & 6.4 & $\mathrm{~ns}$ \\
\hline VA & 41.7 & 28.4 & 10.7 & $*$ & 53.5 & 27.9 & 10.6 & $*$ & 74.7 & 14.7 & 5.6 & $*$ \\
\hline VD & 43.3 & 34.6 & 11.5 & $*$ & 53.2 & 14.9 & 4.9 & $*$ & 62.7 & 8.6 & 2.9 & $*$ \\
\hline $\mathrm{CO}$ & 65.7 & 26.6 & 4.8 & - & 38.2 & 10.9 & 2.0 & - & 57.1 & 13.9 & 2.5 & - \\
\hline \multicolumn{13}{|c|}{ Locus coeruleus (LC) } \\
\hline $\mathrm{AD}$ & 73.1 & 41.9 & 7.7 & $*$ & 54.3 & 23.3 & 4.3 & $*$ & 60.1 & 8.8 & 1.6 & ns \\
\hline $\mathrm{DP}$ & 156.8 & 104.8 & 52.4 & ns & 40.0 & 16.1 & 8.1 & $\mathrm{~ns}$ & 55.2 & 9.8 & 4.9 & ns \\
\hline HD & 203.5 & 31.9 & 16.0 & $* \mathrm{a}$ & 28.6 & 4.0 & 2.0 & $*$ & 62.2 & 8.1 & 4.0 & $\mathrm{~ns}$ \\
\hline VA & 96.0 & 24.3 & 9.2 & $*$ & 43.8 & 6.0 & 2.3 & $\mathrm{~ns}$ & 57.5 & 7.6 & 2.9 & $\mathrm{~ns}$ \\
\hline VD & 135.0 & 47.4 & 15.8 & ns & 36.6 & 11.0 & 3.7 & $\mathrm{~ns}$ & 59.1 & 11.4 & 3.8 & $\mathrm{~ns}$ \\
\hline$C O$ & 133.0 & 45.5 & 8.2 & - & 38.2 & 9.2 & 1.7 & - & 55.1 & 6.2 & 1.1 & - \\
\hline
\end{tabular}

MST, minimal spanning tree; MSNE, number of edges; MMEL, mean edge length (pixel); MSCV, coefficient of variation ( $P$ refers to Student's $t$-test; the significance level is $* P \leqslant 0.05$ for the means of the disease goups as compared with the controls; ns, not significant); SD, standard deviation; SE, standard error of the mean.

${ }^{a}$ This significantly higher number of edges (objects) in HD is mainly due to the age-effect on the locus coeruleus, the mean age being 10 years lower in the HD group than in the controls (highest $F$ for AGE in the analysis of variance).

rior (NCS), the nucleus raphes dorsalis (NRD) and the locus ceruleus (LC) (Tables 2 and 3). In the NCS and the NRD the average loss of neurons reached almost $30 \%$ (Table 3) with a large variation (Table 2), while the distance between neurons, expressed by the mean edge length (MMEL), had increased by $18-24 \%$.

In the LC, the mean decline in neuronal numbers was $45 \%$, with an increase of the neuronal distance of about the same magnitude (42\%).

An analysis of variance with the GLM procedure (Table 4) revealed a major influence of the disease $(F=31.2)$ on the neuronal density, while a less significant effect of age was indicated $(F=6.5)$. Conversely, no age-dependence of the neuronal density could be demonstrated for the NCS and the NRD (Table 4). The standard deviations and coefficients of variation also showed significant differences between $\mathrm{AD}$ and the controls for the nucleus centralis superior (NCS) and the locus ceruleus (LC) (Table 3).

The remaining neurons in the NCS, NRD, and LC were frequently atrophic or showed signs of degen- eration, including abnormal accumulation of lipopigment, changes akin to granulovacuolar degeneration, and occasionally swelling with achromasia (Fig. 3a). In addition, the aminergic nuclei were characterized by both increased formation of neurofibrillary tangles and $\beta / \mathrm{A} 4$ amyloid deposition (Fig. 3(b-i)) which were more abundant in the NCS and NRD than in the LC.

In addition to tangle bearing neurons, many tomb stone tangles could be demonstrated (Fig. 3(b, c)) so that, in some cases, the number of tangles exceeded the number of remaining neurons (NFCO $>1$ ).

The amyloid deposits varied between "mild" and "marked" and consisted mainly of amorphous or diffuse plaques only visible after immunostaining with the $\mathrm{mAb} \mathrm{W}_{0-2}$ for $\beta / \mathrm{A} 4$ amyloid protein (Fig. 3i), including some core plaques (Fig. 3f). Occasionally, neuritic plaques (Fig. $3 \mathrm{~g}$ ) expressed epitopes of the $\mathrm{mAb}$ 22C11 to APP in dystrophic neurites (Fig. 3h). These plaques coincided with plaques in the Bodian silver stains (Fig. 3(e, g)). Raphe vessels also exhibited amyloid in their walls (Fig. 3k). In three AD cases amyloid 
Table 3

Percent change of means in disease groups as compared with the controls $^{\mathrm{a}, \mathrm{b}}$

\begin{tabular}{|c|c|c|c|c|}
\hline \multicolumn{5}{|c|}{ Nucleus centralis superior, pars medialis (NCS) } \\
\hline & MSNE & MMEL & MSSD & MSCV \\
\hline & $\Delta \%$ & $\Delta \%$ & $\Delta \%$ & $\Delta \%$ \\
\hline$\overline{\mathrm{AD}}$ & $-29 *$ & $+18^{*}$ & $+35^{*}$ & $+13^{*}$ \\
\hline HD & $-40^{*}$ & $+36^{*}$ & $+46^{*}$ & +4 \\
\hline VA & $-23^{c}$ & $+18^{\mathrm{c}}$ & $+22 *$ & +1 \\
\hline VD & -10 & +5 & +10 & +3 \\
\hline \multicolumn{5}{|c|}{ Nucleus raphes dorsalis (NRD, pars dorsalis of NCS) } \\
\hline$\overline{\mathrm{AD}}$ & $-27 *$ & $+24 *$ & +26 & +2 \\
\hline HD & -21 & +6 & +2 & -2 \\
\hline VA & $-36^{*}$ & $+40 *$ & $+83^{*}$ & $+31 *$ \\
\hline VD & $-34 *$ & $+39 *$ & $+50^{*}$ & +10 \\
\hline \multicolumn{5}{|c|}{ Locus coeruleus (LC) } \\
\hline $\mathrm{AD}$ & $-45^{*}$ & $+42 *$ & $+57 *$ & $+9 *$ \\
\hline HD & $+53 * \mathrm{~d}$ & $-25^{*}$ & -17 & $+13 *$ \\
\hline VA & $-28 *$ & +14 & $+21^{(*)}$ & +4 \\
\hline VD & +2 & -4 & +6 & +7 \\
\hline
\end{tabular}

MSNE, number of edges; MMEL, mean edge length; MSSD, standard deviation of edge length; MSCV, coefficient of variation of mean edge length.

${ }^{\mathrm{a}}$ Controls $=100 \%$. ${ }^{\mathrm{b}}$ Values labeled with asterisks are significant in the $F$-test, at least at the $P \leqslant 0.05$ level. ${ }^{\mathrm{c}}$ Values receive rather high $F$ for the disease but $P$ remains still below the significance level.

d"Increase" is mainly due to age influence (mean age for HD is 10 years lower than for the control group).

deposits were missing in the NCS, NRD and LC, while tangles were present. All AD cases displayed a considerable cellular gliosis (Table 5) including fibrillary astrocytes and mAb CD68-immunolabeled microglia. Microglia, not only in the vicinity of plaques, was occasionally immunoreactive to $\mathrm{mAb} 22 \mathrm{C} 11$ and $\mathrm{W}_{0-2}$.

In vascular dementia (VD) a non-significant $10 \%$ loss of large neurons in the centralis superior contrasted with a significant reduction by $34 \%$ in the dorsal raphe nucleus (Table 3). The increase of the mean edge length (MMEL) was of about the same magnitude ( 5 and 39\%, respectively). No change became evident in the locus ceruleus (Table 3).

In the "mixed dementia" cases with both vascular and AD-type pathology (VA) the decline in neuronal numbers was bigger than in the VD cases (NCS = $-23 \%, \mathrm{NRD}=-36 \%, \mathrm{LC}=-28 \%$ ) with an increase of the mean edge length (MMEL) (Table 3).

Neurofibrillary tangles (NFT) were infrequent in VD, and amyloid deposits were missing (Table 5). Conversely, in mixed vascular and Alzheimer-type dementia (VA) NFT were frequent, in particular in the nucleus centralis superior, and amyloid deposition could
Table 4

Analysis of variance with the General Linear Models procedure with MST variables for Alzheimer disease (AD) versus controls (CO)

\begin{tabular}{ll}
\hline Model: & Disorder/Age/Gender \\
Dependent variables: & MSNE/MMEL/MSCV
\end{tabular}

Nucleus centralis superior, pars medialis (NCS)

\begin{tabular}{|c|c|c|c|c|c|c|}
\hline & \multicolumn{2}{|c|}{ MSNE } & \multicolumn{2}{|c|}{ MMEL } & \multicolumn{2}{|c|}{ MSCV } \\
\hline & $F$ & $P$ & $F$ & $P$ & $F$ & $P$ \\
\hline DISO & 11.60 & $0.001 *$ & 4.71 & $0.034^{*}$ & 8.58 & $0.005^{*}$ \\
\hline AGE & 0.06 & 0.815 & 1.49 & 0.228 & 0.89 & 0.349 \\
\hline GEND & 0.15 & 0.703 & 0.40 & 0.528 & 1.22 & 0.275 \\
\hline \multicolumn{7}{|c|}{ Nucleus raphes dorsalis (NRD, pars dorsalis of NCS) } \\
\hline DISO & 6.01 & $0.018 *$ & 5.78 & $0.022 *$ & 0.03 & 0.869 \\
\hline AGE & 0.60 & 0.442 & 0.95 & 0.337 & 0.67 & 0.337 \\
\hline GEND & 0.05 & 0.826 & 0.00 & 0.984 & 0.23 & 0.635 \\
\hline \multicolumn{7}{|c|}{ Locus coeruleus (LC) } \\
\hline$\overline{\text { DISO }}$ & 31.12 & $0.0001^{*}$ & 12.30 & $0.001^{*}$ & 7.94 & $0.007 *$ \\
\hline AGE & 6.48 & $0.014 *$ & 0.66 & 0.419 & 1.69 & 0.198 \\
\hline GEND & 0.94 & 0.336 & 1.30 & 0.259 & 0.03 & 0.862 \\
\hline
\end{tabular}

MSNE, number of edges; MMEL, mean edge length (pixel); MSCV, coefficient of variation. The highest $F$ s occur for the disorder (AD) in NCS, NRD, and LC. The age has a significant impact on the number of edges (resp. neurons) in the LC, but no impact on MSNE in the NCS and NRD.

be demonstrated. Cellular gliosis was more prominent in VA than in VD.

A $40 \%$ mean reduction of the number of edges (MSNE) could be demonstrated in Huntington disease (HD) mainly in the centralis superior and to a lesser extent in the dorsal raphe nucleus $(21 \%)$, the mean edge length being increased by $36 \%$ and $6 \%$, respectively. There was no neuron loss in the ceruleus (Tables 2, 3). A few tangles were found in two cases, while amyloid deposits were absent. Gliosis was significant in one of the HD cases.

No changes of the neuronal pattern occurred in the schizophrenia cases (DP) in either of the nuclei (Tables 2-4). Small amounts of tangles, were found in three of the cases, as compared with 14 in the control subjects beyond age 55 (Table 5). Amyloid deposition was absent in the schizophrenia and minimal in three control cases. Gliosis was missing in DP and slightly increasing with age in the control group.

\section{Discussion}

In the present study a graph method was used to examine neuronal patterns of the aminergic brainstem nuclei. Up to now, graph methods were only infrequently 

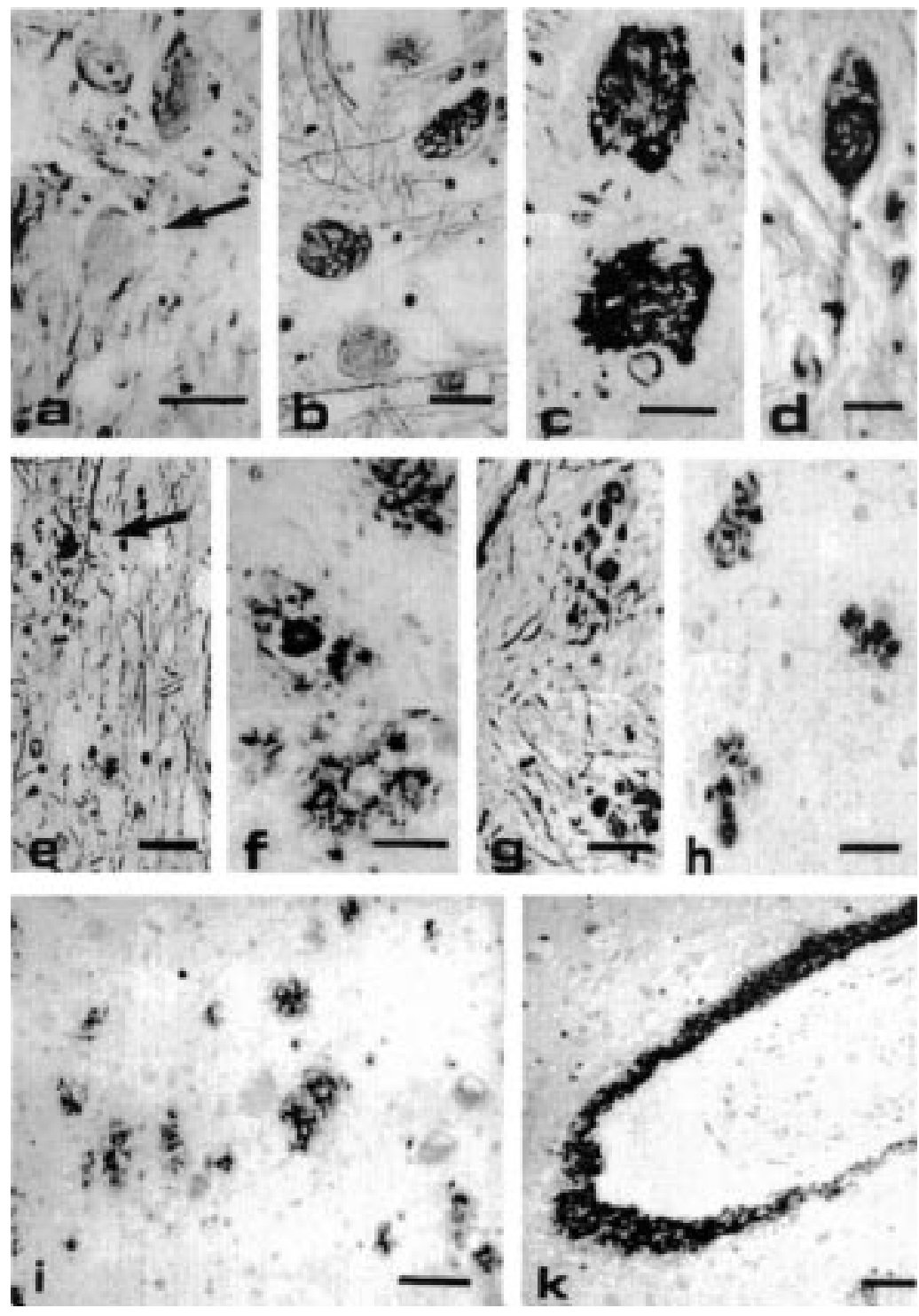

Fig. 3. AD: Histologic findings in the aminergic brainstem nuclei: (a) Degenerating large neurons in the nucleus centralis superior, pars medialis (NCS) with plurivacuolar change akin to granulovacuolar degeneration and neuronal achromasia (arrow, Klüver-Barrera); (b, c) tangle neurons in the NCS (b) and in the LC (Bodian) (c); (d) NCS neuron with tangles containing a round cytoplasmic inclusion body (Bodian); (e) core plaque (arrow, Bodian) and diffuse plaques; (f) immunolabeled with $\mathrm{mAb} \mathrm{W} \mathrm{W}_{0-2}$ to $\beta / \mathrm{A} 4$ amyloid protein in the NCS; (g, h) neuritic plaques with dystrophic axons in the NCS ((g) Bodian, (h) immunoreaction with mAb 22c11 to APP); (i) NCS: amorphous plaques (preplaques); and (k) vascular amyloid labeled with the $\mathrm{mAB} \mathrm{W}_{0-2}$. (Calibration bars represent $50 \mu \mathrm{m}$ in a, h, i, k, and $25 \mu \mathrm{m}$ in b-g.)

employed to analyse object patterns and clusters in biological material. As far as they were applied they have proved to be useful tools to study under normal [28, $60]$ and pathologic $[49,50]$ conditions spatial arrangements of objects in organic tissues, permitting their parametrization for computational purposes.

Minimally connected graphs [88], such as the "minimal spanning tree" (MST), are comparatively easy to compute by means of classical algorithms (cf. $[52,85])$.
They offer results which can also be well assessed visually (Fig. 2).

In this study, the MST $[75,101]$ was used to analyse the pattern of large neurons in the serotoninergic nucleus centralis superior (NCS), including a part of the nucleus raphes dorsalis (NRD) (pars dorsalis of the NCS), as well as in the noradrenergic locus ceruleus (LC). The aminergic neurons were not specifically labeled for their transmitter content. However, it has 
Table 5

Tangle counts, amyloid pathology, and gliosis

\begin{tabular}{|c|c|c|c|c|c|c|c|c|c|c|c|c|}
\hline \multicolumn{13}{|c|}{ Nucleus centralis superior, pars medialis (NCS) } \\
\hline & \multicolumn{3}{|c|}{ NNFT } & \multicolumn{3}{|c|}{ NFCO } & \multicolumn{3}{|c|}{ AMPA } & \multicolumn{3}{|c|}{ GLIO } \\
\hline & Mean & Min & Max & Mean & Min & Max & Mean & Min & $\operatorname{Max}$ & Mean & Min & Max \\
\hline $\mathrm{AD}$ & 16.3 & 0 & 73 & 0.3 & 0 & 2.3 & 1.2 & 0 & 3 & 1.5 & 1 & 2 \\
\hline $\mathrm{DP}$ & 0.5 & 0 & 1 & 0.01 & 0 & 0.01 & 0 & 0 & 0 & 0 & 0 & 0 \\
\hline HD & 0.5 & 0 & 2 & 0.01 & 0 & 0.02 & 0 & 0 & 0 & 1.3 & 0 & 2 \\
\hline VA & 8.3 & 1 & 22 & 0.1 & 0 & 0.3 & 0.9 & 0 & 2 & 1.1 & 0 & 2 \\
\hline VD & 0.4 & 0 & 2 & 0.01 & 0 & 0.03 & 0 & 0 & 0 & 0.8 & 0 & 0 \\
\hline $\mathrm{CO}$ & 1.9 & 0 & 18 & 0.02 & 0 & 0.1 & 0.1 & 0 & 1 & 0.4 & 0 & 2 \\
\hline \multicolumn{13}{|c|}{ Nucleus raphes dorsalis (NRD, pars dorsalis of NCS) } \\
\hline $\mathrm{AD}$ & 11.7 & 1 & 41 & 0.4 & 0.01 & 2.7 & 0.6 & 0 & 3 & 0.9 & 0 & 2 \\
\hline DP & 0.5 & 0 & 1 & 0.0 & 0 & 0.01 & 0 & 0 & 0 & 0 & 0 & 0 \\
\hline HD & 0.8 & 0 & 1 & 0.01 & 0 & 0.03 & 0.3 & 0 & 1 & 1.5 & 1 & 2 \\
\hline VA & 2.7 & 0 & 7 & 0.1 & 0 & 0.3 & 0.6 & 0 & 2 & 0.7 & 0 & 1 \\
\hline VD & 0.4 & 0 & 2 & 0.01 & 0 & 0.1 & 0 & 0 & 0 & 0.3 & 0 & 1 \\
\hline $\mathrm{CO}$ & 1.9 & 0 & 10 & 0.03 & 0 & 0.2 & 0.06 & 0 & 1 & 0.3 & 0 & 2 \\
\hline \multicolumn{13}{|c|}{ Locus coeruleus (LC) } \\
\hline$\overline{\mathrm{AD}}$ & 8.7 & 0 & 31 & 0.2 & 0 & 0.7 & 1.0 & 0 & 3 & 1.3 & 0 & 2 \\
\hline DP & 2 & 0 & 4 & 0.01 & 0 & 0.03 & 0 & 0 & 0 & 0 & 0 & 0 \\
\hline HD & 1.3 & 0 & 4 & 0.01 & 0 & 0.02 & 0 & 0 & 0 & 1 & 1 & 1 \\
\hline VA & 2.7 & 0 & 9 & 0.03 & 0 & 0.14 & 0.6 & 0 & 2 & 0.9 & 0 & 2 \\
\hline VD & 1.4 & 0 & 7 & 0.01 & 0 & 0.03 & 0 & 0 & 0 & 0.4 & 0 & 1 \\
\hline $\mathrm{CO}$ & 1.2 & 0 & 6 & 0.01 & 0 & 0.06 & 0.2 & 0 & 1 & 0.3 & 0 & 1 \\
\hline
\end{tabular}

NNFT, number of neurofibrillary tangles; NFCO, tangle coefficient (= NNFT/number of neurons); AMPA, amyloid pathology; GLIO, cellular gliosis. (Values for NNFT and NFCO are continuous. Values for AMPA and GLIO are semiquantitative. Categories: $\mathrm{AMPA}=0 / 1+/ 2+/ 3+; \mathrm{GLIO}=0 / 1+/ 2+$.)

been shown that aminergic neurons coincide to a high degree with the large ("specific") neurons in the raphe nuclei and the LC $[6,38,39,72]$.

The most significant changes were found in AD. Here, a decline of neuronal arrangements in the serotoninergic raphe nuclei and in the noradrenergic locus ceruleus, associated with tangle pathology and amyloid deposition clearly exceeded the age-related levels in non-demented individuals. The aminergic nuclei displayed an about $30-45 \%$ average decline in the number of specific neurons as compared with the controls. This matches the findings of Jellinger [46] for the dorsal raphe nucleus in Alzheimer-type dementia $(43 \%$, range $36-66 \%)$. In the dorsal raphe nucleus and in the ceruleus, the MST mean edge length had increased proportionately to the neuron loss, which results in the formation of longer edges. Only in the centralis superior the increase of the mean edge length (18\%) was disproportionate to the neuronal loss $(-29 \%)$, which indicates that the thinning of the neuronal texture was discontinuous with a tendency of remaining neurons to cluster.
No age-related decline of large neurons could be demonstrated in the centralis superior and dorsal raphe nucleus by the present and other studies [38,51]. Therefore, the neuron loss in the upper raphe nuclei, which was also observed by other authors $[2,21,25,59$, $91,96,98$ ] can be mainly attributed to disease factors other than aging. Halliday et al. [39] concluded that serotoninergic raphe neurons were selectively affected in Alzheimer disease.

Conversely, in the locus ceruleus a minor proportion of the $45 \%$ decline in neuronal numbers is due to an age-related loss which could be demonstrated by GLM regression analysis. Age-related neuron loss in non-demented controls was also found by other authors $[16,21,44,91,93]$. However, for the present data an analysis of variance showed that the major proportion of the neuronal changes in the locus ceruleus can be attributed to the disease (see also $[15,17,19,20,59$, 61,62]).

The change of neuronal density in the AD cases was accompanied by an increased number of neurofibrillary tangles $[25,34,43,98,99,102,103]$ and by deposits 
of $\beta / \mathrm{A} 4$ amyloid in form of amorphous plaques and core plaques. Some of the latter also contained dystrophic neurites immunoreactive to the amyloid precursor protein monoclonal antibody $22 \mathrm{C} 11$ and were already visible in the Bodian stains (see also [42]). Activated $\beta / \mathrm{A} 4$ and mAB 22C11 immunoreactive microglia were not only associated with plaques and dystrophic neurites [37] but also more diffusely distributed throughout the nucleus centralis superior. A partial linkage of activated microglia with the amount of tangles has been discussed [27].

In general, in $\mathrm{AD}$ the aminergic nuclei displayed the strongest pathologic changes of all lower brainstem nuclei (see also [42]).

The vascular dementia (VD) cases did not show significant alterations of the neuronal pattern in the nucleus centralis superior and the locus ceruleus. Conversely, in the mixed vascular and Alzheimer type dementias (VA) a decrease in neuronal density with a dysproportionate increase of the distance between remaining neurons was found to be of similar magnitude as in $\mathrm{AD}$. This, together with the increased occurrence of tangle and amyloid pathology in the VA cases, suggests that in mixed-type dementia the changes in the upper raphe nuclei and in the ceruleus were mainly due to the Alzheimer component.

In the schizophrenia cases, no significant changes could be demonstrated in the aminergic nuclei by the graph analysis. The DP cases were morphologically indistinguishable from the controls. While some authors reported results in favor of an increased vulnerability of schizophrenics to AD pathology $[76,80]$, other studies appeared to prove the opposite $[56,80,81]$. Some results even suggested a decreased prevalence for ADrelated changes in schizophrenia $[30,69,82]$.

The serotoninergic system has been hypothesized to be involved in schizophrenia [66]. However, this does not seem to be reflected by morphologic changes of the raphe nuclei.

Surprisingly, the four Huntington (HD) cases examined in the present study showed a significant reduction of the neuronal density in the nucleus centralis superior (even more severe than in $\mathrm{AD}$ ) and to a lesser extent in the dorsal raphe nucleus. No changes were found in the locus ceruleus.

Today, only little information about the conditions of the ascending aminergic systems in HD is available from the literature. Enna et al. [31,32] found a decrease of serotonin receptor binding in the caudate nucleus (but not in the cortex), while $\beta$-adrenergic receptor binding was unimpaired. Striatal 5-HT concentra- tions were found to be normal [24] or elevated [10,23]. The latter might reflect a response to a decreased number of 5-HT receptors [31].

The significance of the present findings in the nucleus centralis superior as an additional indication of serotoninergic impairment in Huntington disease has to await further clarification by the study of larger numbers of cases.

The raphe and locus ceruleus neurons extend extensive aminergic fiber projections not only to limbic and neocortical areas, but also to the thalamus, where the truncothalamic (intralaminar and midline) nuclei and the thalamic reticular complex receive the strongest innervation $[4,54]$. Through these widespread projections the raphe and locus ceruleus systems can modulate information flow to the cortex $[65,94]$ by exerting inhibitory or facilitatory influence on the target neurons, which alters their response level to fast amino acid transmission. In this way, the ascending aminergic forebrain systems control complex behavior and higher mental functions, such as emotional and cognitive processing $[45,84]$.

The results of the present study may support the concept that the ascending aminergic systems of the isodendritic brainstem core belong to the preferential targets of the disease process in AD and VA. With respect to the significance of aminergic neuromodulation for cognitive functioning $[45,67,84]$, this favors the presumption that impairment not only of the cholinergic forebrain system [74,97] but also of the serotoninergic [67] and the noradrenergic neuromodulation may represent an important factor in the pathogenesis of the mental decline occurring with Alzheimer disease and mixed vascular and Alzheimer-type dementia. This is in accordance with the results of in vivo studies by positron emission tomography (PET) of the serotoninergic forebrain system in Alzheimer disease. The PET studies demonstrated significant reductions in 5-HT receptor radionuclide binding in AD [14], indicating involvement in the disease of serotoninergic neurotransmission.

\section{Acknowledgement}

The authors are grateful to Mrs Gill Muncke for valuable technical help and linguistic advice. This study was supported by a grant through SFB317 (to K.B.) of the Deutsche Forschungsgemeinschaft and by the "Forschungsförderungsprogramm" of the Faculty of Medicine of the Ruprecht-Karls-University of Heidelberg, Project-No. 167-95 (to H.P.S.). 


\section{References}

[1] G.K. Aghajanian and C.P. VanderMaelen, Specific systems of the reticular core: serotonin, in: Handbook of Physiology, Vol. 4, Sec. I: Neurophysiology, V.B. Mountcastle, F.E. Bloom and S.R. Geiger, eds, Amer. Physiol. Soc., Bethesda, MD, USA, 1986, pp. 237-256.

[2] M.A. Aletrino, O.J.M. Vogels, P.H.M.F. Van Domburg and H.J. Ten Donkelaar, Cell loss in the nucleus raphes dorsalis in the Alzheimer's disease, Neurobiol. Aging 13 (1992), 461468.

[3] S.E. Arnold and J.Q. Trojanowski, Cognitive impairment in elderly schizophrenia: a dementia (still) lacking distinctive histopathology, Schizophr. Bull. 22 (1996), 5-9.

[4] K.G. Baker and G.M. Halliday, Ascending noradrenergic and serotoninergic systems in the human brain stem, in: Neurotransmitters in the Brain. Advances in Behavioral Biology, Vol. 43, D.J. Tracey, G. Paxinos and J. Stone, eds, Plenum Press, New York, 1995, pp. 155-172.

[5] K.G. Barker, G.M. Halliday and I. Törk, Cytoarchitecture of the human dorsal raphe nucleus, J. Comp. Neurol. 301 (1990), 147-161.

[6] K.G. Baker, G.M. Halliday, P. Halasz, J.P. Hornung, L.B. Geffen, R.G.H. Cotton and I. Törk, Cytoarchitecture of serotoninsythesizing neurons in the pontine tegmentum of the human brain, Synapse 7 (1991), 301-320.

[7] M.J. Ball and G.H. Murdoch, Neuropathological criteria for the diagnosis of Alzheimer's disease: are we really ready yet?, Neurobiol. Aging 18 (1997), S3-S12.

[8] M.J. Ball, H. Braak, P. Coleman, D. Dickson, C. Duyckaerts et al., Consensus recom-mendations for the postmortem diagnosis of Alzheimer's disease, Neurobiol. Aging 18(Suppl. 13S) (1997), 1-2.

[9] C. Bancher, K. Jellinger, H. Lassmann, P. Fischer and F. Leblhuber, Correlations between mental state and quantitative neuropathology in the Vienna Longitudinal Study on Dementia, Eur. Arch. Psychiat. Clin. Neurosci. 246 (1996), 137-146.

[10] H. Bernheimer and O. Hornykiewicz, Brain amines in Huntington's chorea, in: Advances in Neurology, Vol. 1: Huntington's Chorea, 1872-1973, A. Barbeau, T. Chase and G.W. Paulson, eds, Raven, New York, 1973, pp. 525-531.

[11] K. Beyreuther and C.L. Masters, Tangle distanglement, $\mathrm{Na}$ ture 383 (1996), 476-477.

[12] K. Beyreuther and C.L. Masters, The ins and outs of amyloid- $\beta$, Nature 389 (1997), 677-678.

[13] L.M. Bierer, P.R. Hof, D.P. Purohit, L. Carlin, J. Schmeidler, K.L. Davis and D.P. Perl, Neocortical neurofibrillary tangles correlate with dementia severity in Alzheimer's disease, Arch. Neurol. 52 (1995), 81-88.

[14] J.Blin, J.C. Baron, B. Dubois, C. Crouzel, M. Fiorelli, D. Attar-Levy, B. Pillon, D. Fournier, M. Vidailhet and Y. Agid, Loss of brain 5-HT2 receptors in Alzheimer's disease. In vivo assessment with positron emission tomography and [18F]setoperone, Brain 116(Pt 3) (1993), 497-510.

[15] W. Bondareff and C. Mountjoy, Number of neurons in locus coeruleus in demented and non-demented patients: rapid estimation and correlated parameters, Neurobiol. Aging 7 (1986), 297-300.
[16] W. Bondareff and C. Mountjoy, Neuronal degeneration in locus ceruleus and cortical correlates of Alzheimer disease, Alzheimer Dis. Assoc. Disord. 1 (1987), 256-262.

[17] W. Bondareff, C.Q. Mountjoy, M. Roth, M.N. Rossor, L.L. Iversen and G.P. Reynolds, Age and histopathologic heterogeneity in Alzheimer's disease. Evidence for subtypes, Arch. Gen. Psychiat. 44 (1987), 412-417.

[18] H. Braak and E. Braak, Neuropathological stageing of Alzheimer-related changes, Acta Neuropathol. (Berl.) 82 (1991), 239-259.

[19] V. Chan-Palay, Alterations in the locus coeruleus in dementias of Alzheimer's and Parkinson's disease, in: Progress in Brain Research, Vol. 88, C.D. Barnes and O. Pompeiano, eds, 1991, pp. 625-630.

[20] V. Chan-Palay and E. Asan, Alterations in catecholamine neurons of the locus coeruleus in senile dementia of the Alzheimer type and in Parkinson's disease with and without dementia and depression, J. Comp. Neurol. 287 (1989), 373392.

[21] V. Chan-Palay, M. Höchli, B. Jentsch, B. Leonard and T. Zetzsche, Raphe serotonin neurons in the human brainstem in normal controls and patients with senile dementia of the Alzheimer type and Parkinson's disease: relationship to monoamine oxidase enzyme location, Dementia 3 (1992), 253-269.

[22] W.J. Conover and R.L. Iman, Rank transformation as a bridge between parametric and nonparametric statistics, Amer. Statistician 35 (1981), 124-129.

[23] B. Costall, A.M. Domeney, M.E. Kelly and R.J. Naylor, Influence of 5-HT on cognitive performance, in: Serotonin, CNS Receptors and Brain Function. Advances in the Biosciences, Vol. 85, P.R. Bradley, S.L. Handley, S.J. Cooper, B.J. Key, N.M. Barnes and J.H. Cooke, eds, Pergamon Press, Oxford, New York, 1992, pp. 147-164.

[24] H. Cramer, Zur Neurochemie der Huntingtonschen Krankheit, in: Die Huntingtonsche Krankheit, G. Deuschl, G. Oepen and G. Wolff, eds, Springer, Berlin, 1988, pp. 128-139.

[25] C.A. Curcio and T. Kemper, Nucleus raphe dorsalis in dementia of Alzheimer type: neurofibrillary changes and neuronal packing density, J. Neuropathol. Exp. Neurol. 43 (1984), 359368.

[26] D.W. Dickson, H.A. Crystal, C. Bevona, W. Horner, I. Vincent and P. Davies, Correlation of synaptic and pathological markers with cognition of the elderly, Neurobiol. Aging 16 (1995), 285-304.

[27] P.L. DiPatre and B. Gelman, Microglial cell activation in aging and Alzheimer disease: partial linkage with neurofibrillary tangle burden in the hippocampus, J. Neuropathol. Exp. Neurol. 56 (1997), 143-150.

[28] C. Dussert, M. Rasigni, J. Palmari, G. Rasigni, A. Llebaria and F. Marty, Minimal spanning tree analysis of biological structures, J. Theoret. Biol. 125 (1987), 317-323.

[29] C. Duyckaerts, J.-P. Brion, J.-J. Hauw and J. Flament-Durand, Quantitative assessment of the density of neurofibrillary tangles and senile plaques in senile dementia of Alzheimer type. Comparison of immunohistochemistry with a specific antibody and Bodian's protargol method, Acta Neuropathol. (Berl.) 73 (1987), 167-170. 
[30] A.J. Dwork, A.S. Susser, J. Keilp, C. Waniek, D. Liu, M. Kaufman, Z. Zemishlany and I. Prohovnik, Senile degeneration and cognitive impairment in chronic schizophrenia, Am. J. Psychiatry 155 (1998), 1536-1543.

[31] S.J. Enna, J.P. Bennett, Jr., D.B. Bylund, S.H. Snyder, E.D. Bird and L.L. Iversen, Alterations of brain neurotransmitter receptor binding in Huntington's chorea, Brain Res. 116 (1976), 531-537.

[32] S.J. Enna, E.D. Bird, J.P. Bennett, Jr., D.B. Bylund, H.J. Yamamura, L.L. Iversen and S.H. Snyder, Huntington's chorea. Changes in neurotransmitter receptors in the brain, New Engl. J. Med. 294 (1976), 1305-1309.

[33] J.D. French, The reticular formation, in: Handbook of Physiology, Section 1, Neurophysiology, Vol. 2, J. Field, H.W. Magoun and V.E. Hall, eds, American Physiological Society, Washington DC, 1960, pp. 1281-1305.

[34] D.C. German and C.L. White, Sparkman DR Alzheimer's disease: neurofibrillary tangles in nuclei that project to the cerebral cortex, Neuroscience 21 (1987), 305-312.

[35] M. Goedert, Tau protein and the neurofibrillary pathology of Alzheimer's disease, Ann. NY Acad. Sci. 777 (1996), 121131.

[36] M. Goedert, M.G. Spillantini and R.A. Crowsher, Tau proteins and neurofibrillary degeneration, Brain Pathol. 1 (1991), 279286.

[37] W.S.T. Griffin, J.G. Sheng, G.W. Roberts and R.E. Mrak, Interleukin-1 expression in different plaque types in Alzheimer's disease: significance in plaque evolution, J. Neuropathol. Exp. Neurol. 54 (1995), 276-281.

[38] G.M. Halliday and K.M. Cullen, Neurotransmitter changes in Alzheimer's disease, in: Neurotransmitters in the Human Brain. Advances in Behavioral Biology, Vol. 43, D.J. Tracey, G. Paxinos and J. Stone, eds, Plenum Press, New York, 1995, pp. 199-219.

[39] G.M. Halliday, H.L. McCann, R. Pamphlett, W.S. Brooks, H. Creasey, E. McCusker, R.G.H. Cotton, G.A. Broe and C.G. Harper, Brain stem serotonin-synthesizing neurons in Alzheimer's disease: a clinicopathological correlation, Acta Neuropathol. 84 (1992), 638-650.

[40] N. Ida, T. Hartmann, J. Pantel, J. Schröder, R. Zerfaß, H. Förstl, R. Sandbrink, C. Masters and K. Beyreuther, Analysis of heterogeneous $\beta \mathrm{A} 4$ peptides in human cerebrospinal fluid and blood by a newly developed sensitive Western blot assay, J. Biol. Chem. 271 (1996), 22 908-22 914.

[41] K. Iqbal and I. Grundke-Iqbal, Molecular mechanism of Alzheimer's neurofibrillary degeneration and therapeutic intervention, Ann. NY Acad. Sci. 777 (1996), 132-138.

[42] E. Iseki, M. Matsushita, K. Kosaka, H. Kondo, T. Ishii and N. Amano, Distribution and morphology of brain stem plaques in Alzheimer's disease, Acta Neuropathol. (Berl.) 78 (1989), 131-136.

[43] T. Ishii, Distribution of Alzheimer's neurofibrillary changes in the brain stem and hypothalamus of senile dementia, Acta Neurophathol. (Berl.) 6 (1966), 181-187.

[44] L.L. Iversen, M.N. Rossor, G.P. Reynolds, R. Hills, M. Roth, C.Q. Mountjoy, S.L. Foote, J.H. Morrison and F.E. Bloom, Loss of pigmented dopamine-beta-hydroxylase positive cells from locus coeruleus in senile dementia of Alzheimer's type, Neurosci. Lett. 39 (1983), 95-100.
[45] B.L. Jacobs and C.A. Fornal, Serotonin and behavior. A general hypothesis, in: Psychopharmacology: The Fourth Generation of Progress, F.E. Bloom and D.J. Kupfer, eds, Raven Press, New York, 1995, pp. 461-469.

[46] K. Jellinger, Quantitative changes in some subcorticl nuclei in aging, Alzheimer's disease and Parkinson's disease, $\mathrm{Neu}$ robiol. Aging 8 (1987), 556-561.

[47] K.A. Jellinger, Neuropathological staging of Alzheimerrelated lesions: the challenge of establishing relations to age, Neurobiol. Aging 18 (1997), 369-375.

[48] K.A. Jellinger and C. Bancher, Proposals for re-evaluation of current autopsy criteria for the diagnosis of Alzheimer's disease, Neurobiol. Aging 18 (1997), S55-S65.

[49] K. Kayser and H. Stute, DNA content and minimum spanning tree in primary and metastatic adenocarcinoma of the lung, Acta Stereol. 8 (1989), 117-121.

[50] K. Kayser, H. Stute and M. Tacke, Minimum spanning tree, integrated optical density and lymph node metastasis in bronchial carcinoma, Analyt. Cell. Pathol. 5 (1993), 225-234.

[51] T.L. Kemper, M.B. Moss, D.L. Rosane and R.J. Killiany, Agerelated neuronal loss in the nucleus centralis superior of the rhesus monkey, Acta Neuropathol. 94 (1997), 124-130.

[52] H. Kolles, H. Ludt, G.H. Vince and W. Feiden, Application of minimal spanning trees in glioma grading - a CLIPPER program for the calculation and construction of minimal spanning trees, Computer Methods and Programs in Biomedicine 42 (1994), 201-206.

[53] H. Lassmann, R. Weiler, R. Fischer, C. Bancher, K. Jellinger, E. Floor, W. Danielczyk, F. Seitelberger and H. Winkler, Synaptic pathology in Alzheimer's disease: immunological data for markers of synaptic and large dense-core vesicles, Neuroscience 46 (1992), 1-8.

[54] B. Lavoie and A. Parent, Serotoninergic innervation of the thalamus in primate: an immunohistochemical study, J. Comp. Neurol. 312 (1991), 1-18.

[55] H.W. Magoun, An ascending reticular activating system in the brain stem, Arch. Neurol. Psychiat. 67 (1952), 145-154.

[56] R.S. el Mallakh, D.G. Kirch, R. Shelton, K.J. Fan, G. Pezeshkpour, S. Kanhouwa, R.J. Wyatt and J.E. Kelinman, The nucleus basalis of Meynert, senile plaques, and intellectual impairment in schizophrenia, J. Neuropsychiat. Clin. Neurosci. 3 (1991), 383-386.

[57] L. Mamournas, M.A. Wilson, K.J. Axt and M.E. Molliver, Morphlogical aspects of serotonergic innervation, in: Serotonin, CNS Receptors and Brain Function. Advances in the Biosciences, Vol. 85, P.B. Bradley, S.L. Handley, S.J. Cooper, B.J. Key, N.M. Barnes and J.H. Coote, eds, Pergamon Press, Oxford, NY, USA, 1992, pp. 97-118.

[58] D. Mann and P. Yates, Serotonin nerve cells in Alzheimer's disease, J. Neurol. Neurosurg. Psychiat. 46 (1983), 96-98.

[59] D.M.A. Mann, P.O. Yates and J. Hawkes, The pathology of the human locus coeruleus, Clin. Neuropathol. 2 (1983), 1-7.

[60] R. Marcelpoil and Y. Usson, Methods for the study of cellular sociology: Voronoi diagrams and parametrization of the spatial relationships, J. Theoret. Biol. 154 (1992), 359-369.

[61] B. Marciniuk, D.M.A. Mann and P.O. Yates, The topography of cell loss from locus coeruleus in Alzheimer's disease, J. Neurol. Sci. 76 (1986), 335-345. 
[62] B. Marciniuk, D.M.A. Mann and P.O. Yates, Loss of nerve cells from locus coeruleus in Alzheimer's disease is topographically arranged, Neurosci. Lett. 64 (1986), 247-252.

[63] C.L. Masters and K. Beyreuther, Alzheimer's disease, Brit. Med. J. (BMJ) 316 (1998), 446-448.

[64] A.C. McKee, K.S. Kosik and N.W. Kowall, Neuritic pathology and dementia in Alzheimer's disease, Ann. Neurol. 30 (1991), 156-165.

[65] D.A. McCormick, Neurotransmitter actions in the thalamus and cerebral cortex and their role in neuromodulation of thalamo-cortical activity, Progr. Neurobiol. 39 (1992), 337 338.

[66] H.Y. Meltzer, Clozapine: mechanism of action in relation to ist clinical advantages, in: Recent Advances in Schizophrenia, A. Kales, C.N. Stefanis and J.A. Talbett, eds, Springer, New York, Berlin, Heidelberg, 1990, pp. 237-256.

[67] C.C. Meltzer, G. Smith, S.T. DeKosky, B.G. Pollock, C.A. Mathis, R.Y. Moore, D.J. Kupfer and C.F. Reynolds, 3rd, Serotonin in aging, late-life depression, and Alzheimer's disease: the emerging role of functional imaging, Neuropsychopharmacology 18 (1998), 407-430.

[68] J.H. Morrison and S.L. Foote, Noradrenergic and serotonergic innervation of cortical, thalamic, and tectal visual structures in old and new world monkeys, J. Comp. Neurol. 243 (1986), 117-118.

[69] G.M. Murphy, Jr., K.O. Lim, M. Wieneke, W.G. Ellis, L.S. Forno, A.L. Hoff and T. Nordahl, No neuropathologic evidence for Alzheimer's disease among elderly schizophrenics, Biol. Psychiatry 43 (1998), 205-209.

[70] Z. Nagy, M.M. Esiri, K.A. Jobst, J.K. Morris, E.M.-F. King, B. McDonald, S. Litchfield and A. Smith, Relative roles of plaques and tangles in dementia of Alzheimer's disease: correlation using three sets of neuropathological criteria, Dementia 6 (1995), 21-31.

[71] R.L. Neve and N.K. Robakis, Alzheimer's disease: a reexamination of the amyloid hypothesis, Trends Neurosci. (TINS) 21 (1998), 15-19.

[72] R. Nieuwenhuys, Cytoarchitecture of the Brain, Springer, Berlin, Heidelberg, NY, 1985.

[73] R. Nieuwenhuys, J. Voogel and Ch. Van Huijzen, The Human Central Nervous System. A Synopsis and Atlas, 3rd edn, Springer, Berlin, Heidelberg, NY, 1988.

[74] J.F. O'Callaghan, An alternative definition for 'neighborhood of a point', IEEE Transact. Comput. 24 (1975), 1121-1125.

[75] A. Nordberg, In vivo detection of neurotransmitter changes in Alzheimer's disease, Ann. NY Acad. Sci. 695 (1993), 27-33.

[76] R.J. Oken and P.L. McGeer, Schizophrenia, Alzheimer's disease, and anti-inflammatory agents 22 (1996), 1-4.

[77] J. Olszewski and D. Baxter, Cytoarchitecture of the Human Brain Stem, 2nd edn, Karger, Basel, 1982.

[78] P. Powchik, M. Davidson, C.B. Nemeroff, V. Haroutunian, D. Purohit, M. Losonczy, G. Bissette, D. Perl, H. Ghanbari, B. Miller et al., Alzheimer's-disease-related protein in geriatric schizophrenic patients with cognitive impairment, Am.J. Psychiatry 150 (1993), 1726-1727.

[79] R.C. Prim, Shortest connection networks and some generalizations, Bell Sys. Tech. J. 36 (1957), 1389-1401.
[80] I. Prohovnik, A.J. Dwork, M.A. Kaufman and N. Willson, Alzheimer-type neuropathology in elderly schizophrenia, Schizophr. Bull. 19 (1993), 805-816.

[81] D.P. Purohit, M. Davidson, D.P. Perl, P. Powchik, V.H. Haroutunian, L.M. Bierer, J. McCrystal, M. Losonczy and K.L. Davis, Severe cognitive impairment in elderly schizophrenic patients: a clinicopathological study, Biol. Psychiatry 33 (1993), 255-260.

[82] D.P. Purohit, D.P. Perl, V.H. Haroutunian, P. Powchik, M. Davidson, J. McCrystal and K.L. Davis, Alzheimer disease and related neurodegenerative diseases in elderly patients with schizophrenia: a postmortem neuropathologic study of 100 cases, Arch. Gen. Psychiatry 55 (1998), 205-211.

[83] E. Ramon-Moliner and W.J.H. Nauta, The isodendritic core of the brain stem, J. Comp. Neurol. 126 (1966), 311-336.

[84] T.W. Robbins and B.J. Everitt, Central norepinephrine neurons and behavior, in: Psychophamacology. The Fourth Generation of Progress, F.E. Bloom and D.J. Kupfer, eds, Raven Press, New York, 1995, pp. 363-372.

[85] F.J. Rohlf, A probabilistic minimum spanning tree algorithm, Information Processing Letters 7 (1978), 44-48.

[86] R. Shi, M.E. Key and K.L. Kalra, Antigen retrieval in formalin-fixed, paraffin-embedded tissues: an enhancement method for immunohistochemical staining based on microwave oven heating of tissue sections, J. Histochem. Cytochem. 39 (1991), 741-748.

[87] G.G. Simpson, A. Roe and R.C. Lewontin, Quantitative Zoology, Chapter 11: Correlation and regression, Harcourt, Brace \& World, New York, 1960, pp. 213-257.

[88] H.A. Sneath and R.R. Sokal, Numerical Taxonomy, Section 5.7: Graphs and Trees, WH Freeman \& Co, San Francisco, 1973, pp. 253-256.

[89] S.H. Snyder, Drugs and the Brain, Scientific American Books Inc., New York, 1986.

[90] P.C. Spector, J.H. Goodnight, J.P. Sall and W.S. Sarl, The GLM procedure, in: SAS ${ }^{\circledR}$ User's Guide: Statistics, 5th edn, SAS Institute Inc., Cary, NC, USA, 1985, pp. 433-506.

[91] M. Tabaton, A. Schenone, P. Romagnoli, G.L. Mancardi, A quantitative and ultrastructural study of substantia nigra and nucleus centralis superior in Alzheimer's disease, Acta Neuropathol. (Berl.) 68 (1985), 218-223.

[92] R.D. Terry, E. Masliah, D.P. Salmon, N. Butters, R. DeTeresa, R. Hill, L.A. Hansen and R. Katzman, Physical basis of cognitive alterations in Alzheimer's disease: synapse loss is the major correlate of cognitive impairment, Ann. Neurol. 30 (1991), 572-580.

[93] B.E. Tomlinson, D. Irving and G. Blessed, Cell loss in the locus coeruleus in senile dementia of Alzheimer type, J. Neurol. Sci. 49 (1981), 419-428.

[94] R.J. Valentino and G.S. Aston-Jones, Physiological and anatomical determinants of locus coeruleus discharge: behavioral and clinical implications, in: Psychopharmacology. The Fourth Generation of Progress, F.E. Bloom and D.J. Kupfer, eds, Raven Press, New York, 1995, pp. 373-386.

[95] A. Weidemann, G. König, D. Bunke, P. Fischer, J.M. Salbaum, C.L. Masters and K. Beyreuther, Identification, biogenesis, and localization of precursors of Alzheimer's disease A4 amyloid protein, Cell 57 (1989), 115-126. 
[96] G. Wilcock, M. Esiri, D. Bowen and A. Hughes, The differential involvement of subcortical nuclei in senile dementia of Alzheimer's type, J. Neurol. Neurosurg. Psychiat. 51 (1988), 842-849.

[97] D. Wyper, J. Owens, D. Brown, J. Patterson, W. Watson, R. Hunter and J. McCulloch, Abnormalities in cerebral muscarinic acetylcholine receptors measured in vivo with SPECT in patients with Alzheimer's disease, Neurobiol. Aging 13(Suppl. 1S) (1992), 23.

[98] M. Yamada and P. Mehraein, Verteilungsmuster der senilen Veränderungen in den Hirnstammkernen, Folia Psychiat. Neurol. Japon 31 (1977), 219-224.

[99] T. Yamamoto and A. Hirano, Nucleus raphe dorsalis in Alzheimer's disease: neurofibrillary tanges and loss of large neurons, Ann. Neurol. 17 (1985), 573-577.

[100] Y. Yang, H.P. Schmitt, G. Multhaup and K. Beyreuther, Microwave enhancement of $\beta / \mathrm{A} 4$ amyloid precursor pro- tein (APP) and $\beta / \mathrm{A} 4$ amyloid peptide (AP) immunoreactivity in formalin-fixed and paraffin-embedded neural tissues of Alzheimer disease and various CNS disorders, $\mathrm{Clin}$. Neuropathol. 14 (1995), 296 (Abstr.).

[101] C.T. Zahn, Graph-theoretical methods for detecting and describing gestalt clusters, IEEE Transact. Comput. 20 (1971), 68-86.

[102] R.M. Zweig, C.A. Ross, J.C. Hedreen, C. Steele, J.E. Cardillo, R.J. Whitehouse, M.F. Folstein and D. Price, The neuropathology of aminergic nuclei in Alzheimer's disease, Ann. Neurol. 24 (1988), 233-242.

[103] R.M. Zweig, C.A. Ross, J.C. Hedreen, C. Steele, J.E. Cardillo, P.J. Whitehouse, M.F. Folstein and D.L. Price, Neuropathology of aminergic nuclei in Alzheimer's disease, Prog. Clin. Bio. Res. 317 (1989), 353-365. 


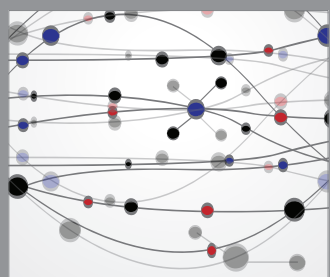

The Scientific World Journal
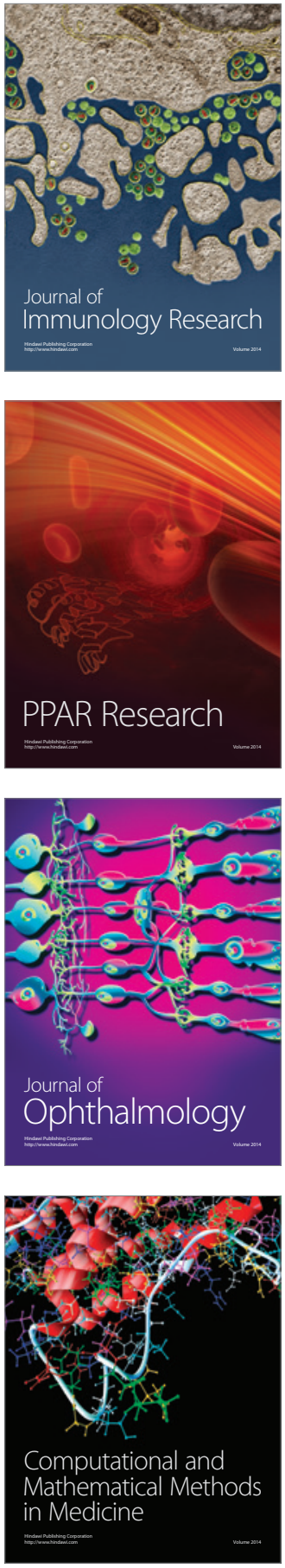

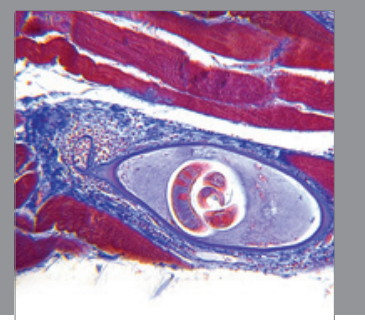

Gastroenterology

Research and Practice
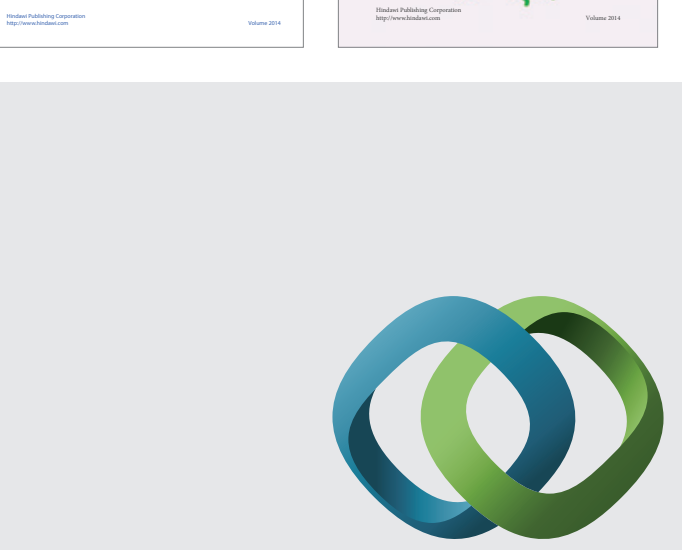

\section{Hindawi}

Submit your manuscripts at

http://www.hindawi.com
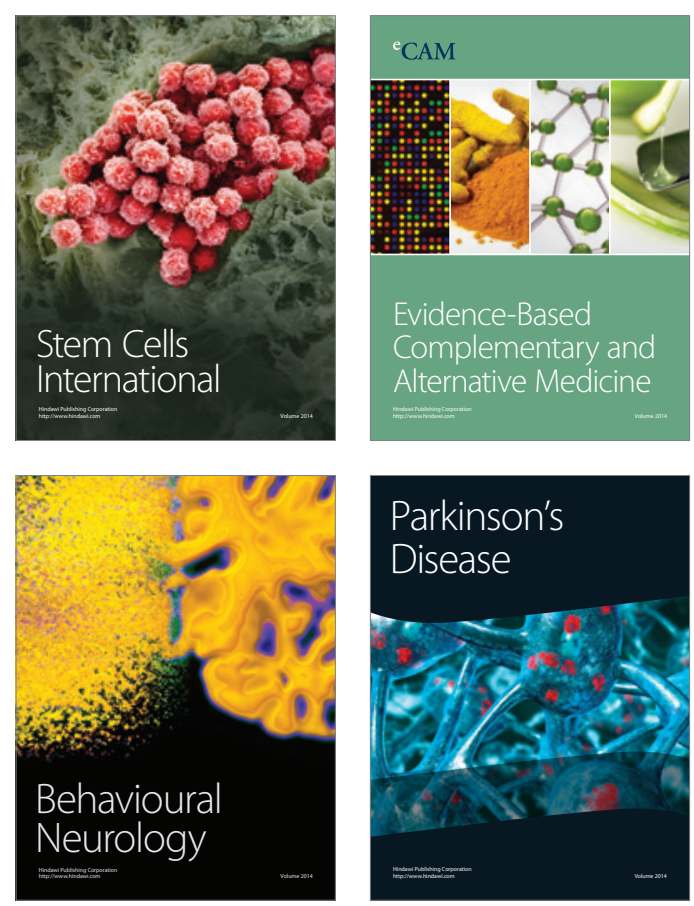

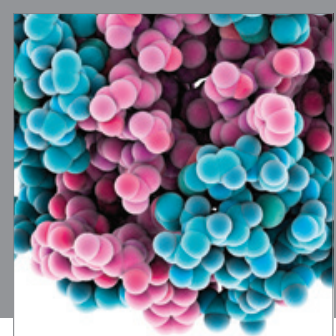

Journal of
Diabetes Research

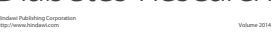

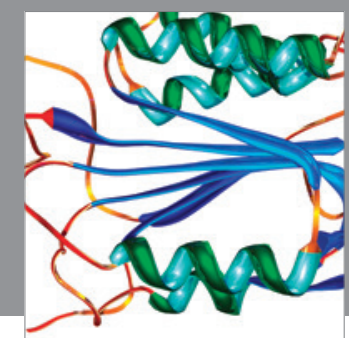

Disease Markers
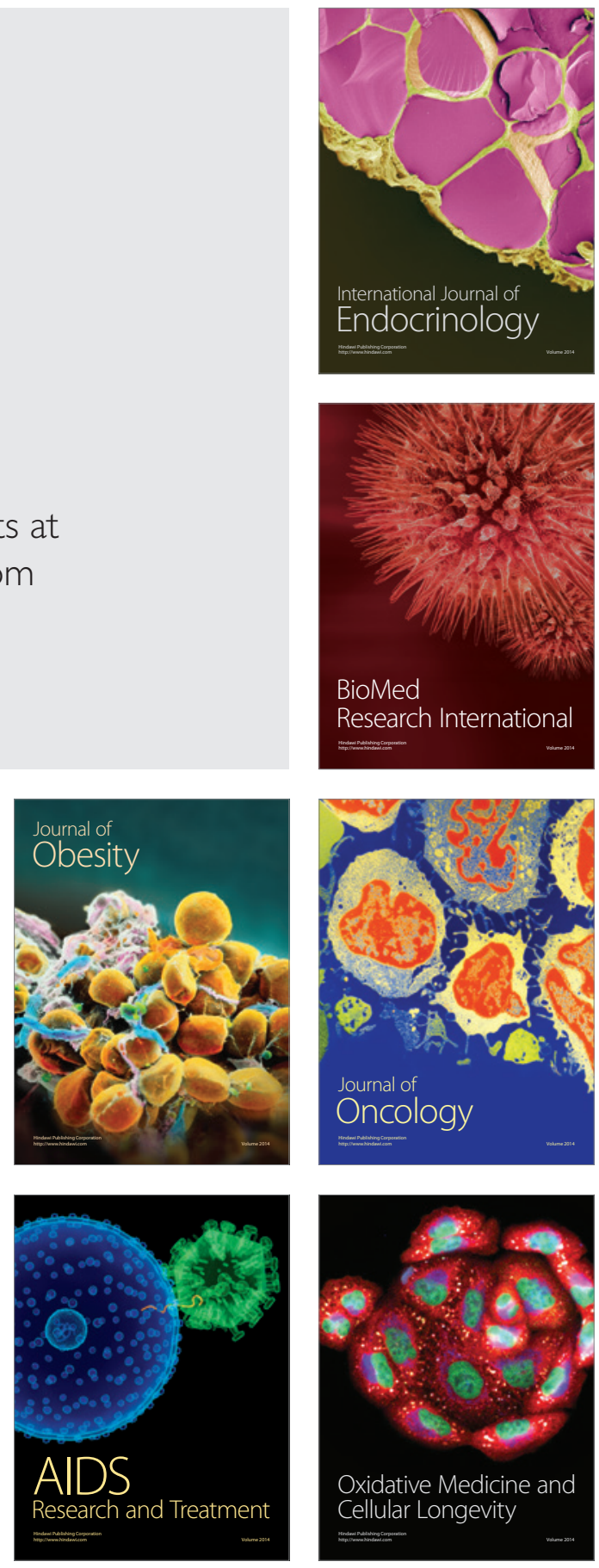